\title{
International Consortium on Prostate Cancer Genetics
}

National Cancer Institute

\section{Source}

National Cancer Institute. International Consortium on Prostate Cancer Genetics. NCI

Thesaurus. Code C19259.

International consortium of over 25 groups and multiple investigators pursuing

collaborative research on the epidemiology of prostate cancer. The consortium was first promoted and supported by the NCl's Epidemiology and Genetics Program in 1995. Investigators are funded primarily by the $\mathrm{NCl}$ for their individual research projects (R01s) while the National Institute for Human Genome Research contributes an intramural component. Current research focuses primarily on the discovery and characterization of prostate cancer susceptibility genes. Collaborations are established through communications and agreements with the participating groups. 